\title{
Agroecologia: saberes e práticas locais como componentes do Bem Viver
}

\author{
Agroecologia: saberes y practicas como componentes de Bem Viver \\ Agroecology: local knowledge and practices as components of Well-Living
}

\author{
Luciane Cristina Ribeiro dos Santos ${ }^{1}$ \\ Franciele Lourenço ${ }^{2}$ \\ Isabel Jurema Grimm ${ }^{3}$ \\ Iala Serra Queiroz ${ }^{4}$ \\ Nívea Maria de Oliveira Silva ${ }^{5}$ \\ Osíris Canciglieri Junior ${ }^{6}$
}

\begin{abstract}
Resumo
Este estudo visa identificar e analisar os benefícios das inovações e transformações tecnológicas em prol do meio ambiente a partir da transição agroecológica, em uma perspectiva do Bem Viver. Metodologicamente, trata-se de pesquisa bibliográfica, com cunho exploratório e descritivo. O estudo ocorreu no Município de Maracás no semiárido do estado da Bahia, entre os territórios, do Vale do Jiquiriçá e do Médio Rio de Contas. Como resultado, foi possível identificar que nas comunidades estudadas existe uma riqueza de saberes e os principais benefícios observados foram a capacidade organizativa, a melhoria dos sistemas produtivos, a conservação ambiental dos recursos naturais e a valorização da sociobiodiversidade a partir do resgate e do uso de sementes crioulas, a segurança alimentar e nutricional com a diversificação dos plantios, como milho, feijão, ervilha, mandioca, andu, palma, frutas, hortaliças, além disso observou a geração de renda a partir da Feira da Diversidade Cultura e Agroecológica. De modo geral, podemos compreender que esses benefícios podem ser entendidos como um processo de Bem Viver agroecológico. Por outro lado, a preocupação refere-se ao Bem Viver dos camponeses da região, que são prejudicados com a falta de pastos para alimentar os animais e a falta de água para irrigação das lavouras, isso devido a degradação ambiental e as mudanças climáticas na região. Conclui-se que as inovações e transformações tecnológicas podem contribuir para o Bem Viver, diante da transição agroecológica, e de políticas públicas que proponham e garantam uma produção mais sustentável e de baixo carbono.
\end{abstract}

Palavras-Chave: Bem Viver; Agroecologia; Capitalismo.

\section{Resumen}

\footnotetext{
${ }^{1}$ Doutoranda em Engenharia de Produção e Sistemas; Pontifícia Universidade Católica do Paraná - PUCPR; Curitiba, Paraná, Brasil; lu.ribeirocrs@hotmail.com. Trabalho apresentado no I Seminário Latino-Americano de Estudos em Cultura - SEMLACult, Foz do Iguaçu/PR, Brasil, 2017.

${ }^{2}$ Mestre em Organizações e Desenvolvimento; Centro Universitário Autônomo do Brasil - UNIBRASIL; Curitiba, Paraná, Brasil; francielelourenco@gmail.com

${ }^{3}$ Pós doutoranda em Gestão Urbana pelo Programa de Pós-Graduação da Pontifícia Universidade Católica do Paraná. Curitiba. PR. isabelgrimm@gmail.com

${ }^{4}$ Mestranda pelo Programa de Pós-graduação em Educação e Contemporaneidade; Universidade do Estado da Bahia - UNEB; e-mail: iala.queiroz@gmail.com

${ }^{5}$ Mestre em Zoologia Aplicada pelo Programa de Pós-Graduação em Zoologia; Universidade Estadual de Santa Cruz - UESC; e-mail: niveagricultura@gmail.com

${ }^{6} \mathrm{PhD}$ em automação da manufatura; Programa de Pós-Graduação em Engenharia de Produção e Sistemas da Pontifícia Universidade Católica do Paraná (PPGEPS/PUCPR), Curitiba/PR, Paraná, Brasil;
} osiris.canciglieri@pucpr.br 
Este estudio busca identificar y analizar los beneficios de las innovaciones y transformaciones tecnológicas en pro del medio ambiente a partir de la transición agroecológica, en una perspectiva del Bien Vivir. Metodológicamente, se trata de una investigación bibliográfica, con un marco exploratorio y descriptivo. El estudio ocurrió en el Municipio de Maracás en el semi árido del estado de Bahía, entre los territorios, del Valle del Jiquiriçá y del Medio Río de Cuentas. Como resultado, fue posible identificar que en las comunidades estudiadas existe una riqueza de saberes y los principales beneficios observados fueron la capacidad organizativa, la mejora de los sistemas productivos, la conservación ambiental de los recursos naturales y la valorización de la socio biodiversidad a partir del rescate y del uso de Las semillas criollas, la seguridad alimentaria y nutricional con la diversificación de los plantíos, como maíz, frijol, guisante, mandioca, andu, palma, frutas, hortalizas, además observó la generación de ingresos a partir de la Feria de la Diversidad Cultura y Agro ecológica. En general, podemos comprender que estos beneficios pueden ser entendidos como un proceso de Bien Vivir agro ecológico. Por otro lado, la preocupación se refiere al Bien Vivir de los campesinos de la región, que son perjudicados por la falta de pastos para alimentar a los animales y la falta de agua para irrigación de los cultivos, debido a la degradación ambiental y los cambios climáticos en la región. Se concluye que las innovaciones y transformaciones tecnológicas pueden contribuir al Bien Vivir, ante la transición agroecológica, y de políticas públicas que propongan y garanticen una producción más sostenible y de bajo carbono.

Palavras-Chave: Bem Viver; Agroecologia; Capitalismo

\begin{abstract}
This study aims to identify and analyze the benefits of innovations and technological transformations in favor of the environment from the agroecological transition, from a perspective of the "Well-Living". Methodologically, this is a bibliographic research, within an exploratory and descriptive profile. The study was carried out in the Maracás Municipality in the semi-arid state of Bahia, between the territories of the Jiquiriçá Valley and Rio de Contas. As a result, it was possible to identify among the communities already studied, that exists a wealth of knowledge where the main benefits observed were organizational capacity, improvement of production systems, environmental conservation of natural resources and valorization of socio-biodiversity from the rescue and use of Creole seeds, also the food and nutrition are guaranteed with the diversification of plantations, such as corn, beans, peas, cassava, andu, palm, fruits, vegetables, which is observed how income generation at the Culture and Agroecological Diversity Fair. In general, we can understand that these benefits could be understood as such as an agroecological well-being process. On the other hand, the main concern is about to the "well-living" of the peasants in that region, who are harmed by the lack of pastures to feed the animals and the lack of water for irrigation of the plantations, due to the environmental degradation and the climatic changes in the region. It can be concluded that technological innovations and transformations can contribute to the Well Living, in view of the agroecological transition, and public policies that propose and guarantee a more sustainable and low carbon production.
\end{abstract}

Keywords: Well Living; Agroecology; Capitalism.

\title{
1. Introdução
}

Contemporaneamente, a existência humana segue orientada pela lógica capitalista, parametrizada pela acumulação e reprodução ampliada do capital, exigindo a mercantilização da vida e da natureza em sua totalidade. Identificar e analisar os preceitos do Bem Viver e do desenvolvimento sustentável, torna-se um desafio diante de tal contexto.

O Bem Viver "se relaciona a qualidade de vida e remete a questões como espiritualidade, natureza, modos de vida e consumo, política, ética" (ALCANTARA \& SAMPAIO, 2017, p. 01), e pode ser percebido como uma proposta de desenvolvimento, onde as bases comunitárias estão orientadas por princípios diferentes dos que propagam o capitalismo. Entendido como uma maneira de visualizar as vulnerabilidades socioeconômicas 
e ambientais das comunidades, promove uma crítica substancial à própria ideia de desenvolvimento, baseado nos conhecimentos e saberes e numa nova forma de convivência, em diversidade e harmonia com a natureza (ALCANTARA \& GRIMM, 2017).

Ancorado em saberes e sensibilidades dos povos indígenas, o Bem Viver está formalizado nas novas Constituições da Bolívia (aprovada em 2009) e do Equador (2008), e pode ser entendido como espaço para o debate político sobre as alternativas ao desenvolvimento, onde embora haja uma diversidade e superposição de diferentes posturas, de qualquer modo há elementos críticos em comum (GUDYNAS \& ACOSTA 2016). Este espaço político de acordo com os autores, reflete numa disposição de encontro, diálogo e interações entre diferentes saberes e afetos e que, dessa maneira, configuram comunidades ampliadas.

Neste sentido este artigo tem como objetivo identificar e analisar os benefícios das inovações e transformações tecnológicas em prol do meio ambiente a partir da transição agroecológica, em uma perspectiva do Bem Viver.

Metodologicamente, trata-se de pesquisa bibliográfica, com cunho exploratório e de análise de caso. O estudo ocorreu no Município de Maracás no semiárido do estado da Bahia, entre os territórios, do Vale do Jiquiriçá e do Médio Rio de Contas.

Os resultados indicam que as inovações e transformações tecnológicas contribuem para o chamado Bem Viver a partir da transição agroecológica e políticas públicas que direcionam para uma produção e manejo dos recursos naturais orientada para à sustentabilidade.

\section{Agroecologia}

Em busca de novas técnicas agrícolas sustentáveis, a partir de 1990, movimentos rurais vêm buscando novas estratégicas de desenvolvimento que aliem produção de menor impacto ambiental e consumo mais consciente. Com vistas a diminuir as agressões ao meio ambiente, ajuste de capital e de tecnologia vem sendo feitos na agricultura convencional, a fim de torná-la viável economicamente.

A ciência da agroecologia é definida por Altieri (2012, p.104) “ como a aplicação dos conceitos e princípios ecológicos para desenhar agroecossistemas sustentáveis [...] vai além do uso de práticas alternativas e do desenvolvimento de agroecossistemas com baixa dependência de agroquímicos e de aportes externos de energia”. 
Esse contexto visa estudar, projetar e manejar agrossistemas (agro - produção agrícola; eco - ambiente natural; sistema - conjunto de elementos/ componentes que atuam relacionados entre si, e que são interdependentes) que sejam produtivos e que ao mesmo tempo tenham condições de conservar seus recursos naturais. Pode-se considerar como um dos principais objetivos da agroecologia o de permitir a recuperação da fertilidade dos solos sem o uso de fertilizantes minerais ou agrotóxicos e, além disso, que a cadeia produtiva leve em conta o sistema de trabalho e as particularidades socioeconômicas e culturais da região e das comunidades locais (ASSIS, 2006).

A agroecologia preza os aspectos ambientais, sociais, culturais, éticos e políticos da agricultura, além das formas de produção ecologicamente mais sadias e sustentáveis, ou seja, considera que a natureza não é um apanhado de recursos que se possa utilizar indiscriminadamente e nem uma máquina a serviço do homem.

Neste sentido, percebe-se a necessidade de analisar a agroecologia por meio da visão sistêmica, para que se possa entender todas as relações existentes, por sua vez a agricultura convencional possui uma visão linear, e conta com o apoio da tecnologia para acelerar os resultados e garantir maior lucro por meio de processos que envolvem realização de estudo de terreno, técnicas modernas de plantio e colheita e controle de pragas com aplicação de agrotóxicos, etc.

Em geral, os alimentos produzidos pela agricultura convencional são maiores, mais vistosos e abundantes, produzidos em larga escala, porém, menos saudáveis. Essa agricultura agressiva, rompe o equilíbrio biológico, ecológico e degrada a natureza. Em contrapartida a agroecologia busca a inclusão social, a qual surge a partir do momento que as pessoas passam a utilizá-la para o seu sustento, assim como as condições de integração, que acabam, por gerar troca de conhecimento quanto aos estudos, técnicas de produção e a própria colheita. A agroecologia por visar a preservação do meio ambiente, faz com que o modo de plantio agrida o menos possível o meio ambiente.

O desafio, portanto, está em reverter os problemas ocasionados pelas perdas modernas - custos ambientais, econômicos e a dependência química. Isso é possível, de acordo com Altieri (2012, p. 139-140) por meio de três fases:

Aumento da eficiência do uso de insumos por meio de manejo integrado de pragas ou do manejo integrado de fertilidade do solo;

$\checkmark$ Substituição de insumos ou substituição por insumos ambientalmente benéficos; 
Redesenho dos sistemas: diversificação por meio de uma combinação de lavouras e criação de animais o que incentiva o sinergismo de modo que o próprio agroecossistema possa viabilizar sua fertilidade do solo, a regulação natural de pragas e a produtividade das culturas.

Entretanto, não se pode considerar que esta seja uma tarefa simples, fácil de ser implantada, percebe-se que a substituição do agrotóxico por produtos de base biológica ou até mesmo a eficiência dos insumos, geram perda do potencial de produção, caso contrário, se estaria apenas transferindo tecnologia de um lugar para o outro sem interações ecológicas e que poderiam ser replicadas, dado que cada sistema de produção utiliza técnicas de manejo diferentes.

Pode-se supor então que a agricultura menos impactante se preocupa com a interação entre as mais diversas áreas envolvidas com o processo de produção, tais como: participação dos agricultores, independência de insumos externos, segurança alimentar, etc., enquanto a comercial não se preocupa com a integração total das áreas, prezando mais o volume produtivo e a relação custo benefício, do que as áreas que permitem vantagens qualitativas e de resultados sustentáveis.

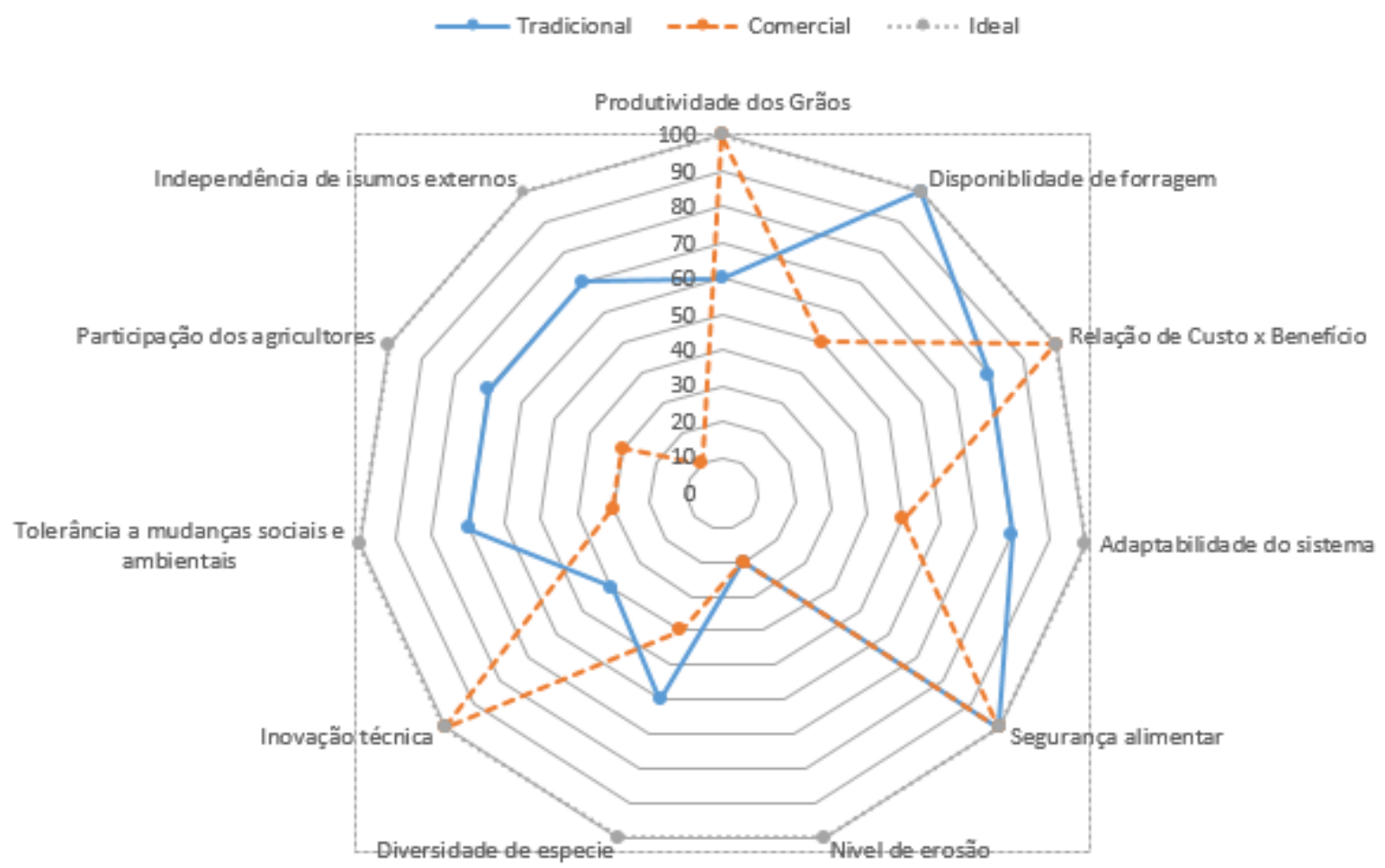

Gráfico 1: comparação das vantagens e limitações dos sistemas de cultivo

Fonte: Altieri, 2012, p. 145. 
No gráfico acima observa-se que é possível avaliar a sustentabilidade, não deixando de conservar os recursos naturais, as necessidades do agricultor e as do gestor do sistema, ou seja, são necessárias modificações e adaptações que atendam, principalmente, os tipos de agricultura comercial e ideal.

\section{Procedimentos Metodológicos}

Este estudo foi desenvolvido a partir de pesquisa bibliográfica, classificada como exploratória descritiva entendida por Gil (2008), como um estudo guiado pelo objetivo geral onde o pesquisador pode seguir três passos de pesquisa: i) pesquisa exploratória; ii) pesquisa descritiva e iii) pesquisa explicativa.

Assim, este estudo foi desenvolvido a partir de uma pesquisa exploratória-descritiva, com o auxílio da pesquisa bibliográfica como procedimento metodológico. A pesquisa bibliográfica desenvolvida enquanto estudo teórico elaborado a partir da reflexão e análise de documentos publicados, originais primários denominados como fontes (SALVADOR, 1986).

O estudo de campo foi realizado junto a 100 (cem) famílias distribuídas nas comunidades rurais do Município de Maracás, conhecida como Candial e Quatro Lagoas, Cachoeirinha e Gavião. As comunidades estão localizadas entre os territórios do Vale do Jiquiriçá e do Médio Rio de Contas, no sudoeste da Bahia, no munícipio de Maracás, na Rodovia BA-330. Vale ressaltar que a comunidade Candial e Quatro Lagoas possui ligação com mais duas comunidades, que é a comunidade de Mulungu e Matão (comunidade quilombola ainda em processo de reconhecimento junto a Fundação Palmares), juntas representam um total de 40 (quarenta) famílias. O Município de Maracás possui aproximadamente $25 \mathrm{mil}$ habitantes e cerca $38 \%$ dessa população vive na zona rural (IBGE, 2010). Diante desses números podemos perceber o quanto é significativo a população da área rural, e o quanto se faz necessário elaborar políticas públicas para estas localidades.

Foram observados os aspectos socioeconômico e o ambiental. No que tange o aspecto socioeconômico, a renda familiar, dos agricultores, vem, sobretudo, da agricultura de pequeno porte, com plantios de mandioca, milho, melancia, abóbora, feijão, maxixe, arroz vermelho, maracugina, girassol preto e sorgo sendo esses últimos para alimentação animal, a exemplo de porcos e galinhas, outros são lavradores diaristas e vaqueiros em outras propriedades rurais. As mulheres cultivam horta de subsistência nos quintais, cuidam das galinhas e pastoreiam pequenos rebanhos de caprinos, em sua maioria são dependentes do programa de transferência de renda como o "Bolsa Família". As comunidades trabalham por meio de mutirões, assim as 
famílias se reúnem para limpar roça, consertar casas, plantar e colher, isso tem sido uma estratégia de fortalecimento e organização do sistema produtivo das famílias.

Desde 2013, as comunidades vêm sendo comtemplada com projetos ligados a convivência com o semiárido de acesso a água, com a construção de cisternas, contribuindo com a mobilização e articulação local, dando autonomia e fortalecendo o protagonismo dessas pessoas. Com relação as manifestações culturais, a comunidade celebra festas tradicionais como os festejos juninos e as rezas do Terno de Reis.

Sob o aspecto ambiental, a região é entrecortada por rios, lagoas e riachos banhados pela bacia hidrográfica do Rio Jiquiriçá, com formações de Mata de Cipó na transição dos biomas Mata Atlântica e Caatinga. Seus ecossistemas apresentam uma elevada variedade de flora e fauna, entre espécies de árvores nativas encontradas temos: a barriguda, o pau ferro, o mulungu, tamburi, mandacaru, xique-xique, o umbuzeiro, a catingueira, o angico, dentre muitas outras que segundo os moradores mais antigos era muito mais abundante. Hoje em dia, se vê uma espécie muito espaçada uma da outra, e o resultado disso é a falta de manejo sustentável do solo, o cultivo de monoculturas e a pecuária extensiva. O uso descontrolado do fogo, o desmatamento de morros e a retira da mata ciliar resultaram em erosão, fuga de fauna e a escassez dos mananciais hídricos, comprometendo o abastecimento das famílias, o consumo dos animais e a irrigação das lavouras.

\section{Análise e discussão}

\subsection{Benefícios das Inovações e transformações tecnológicas em prol do Meio Ambiente a partir da transição ecológica, em uma perspectiva do Bem Viver.}

Contemporaneamente, a sociedade tem buscado de forma incessante o desenvolvimento, como meio de alcançar prosperidade e progresso.

Foi na Carta das Nações Unidas de 1945 e na Conferência de São Francisco, que já se traziam as discussões sobre o desenvolvimento, junto com a criação da Organização das Nações Unidas (ONU), dando origem aos propósitos e meios de se conseguir chegar ao desenvolvimento. E, em meio a tantos tipos de desenvolvimento busca-se com nomes e conceitos reinventados a cada instante, porém, não questionados.

Para Oliveira e Souza-Lima (2006, p. 19) "O desenvolvimento pode ser encarado como um processo complexo de mudanças e transformações de ordem econômica, política e, principalmente, humana e social”.

Por muito tempo desenvolvimento foi entendido como sinônimo de crescimento econômico. O desenvolvimento deve envolver fatores sociais, culturais e políticos, porém sua 
ênfase se baseia no crescimento econômico, o que não é suficiente para outorgar o desenvolvimento de um território. Ele deve ser visto também como fruto de relação de conflito, competição, cooperação e reciprocidade entre atores, interesses e projetos de natureza social, política e cultural. Indicadores econômicos isolados, portanto, não são suficientes para aferir o estágio de avanço social.

Entre a maioria dos estudiosos, ainda não existe o consenso de que o crescimento econômico contém em si a solução para os problemas sociais como a pobreza, poluição, recursos naturais limitados; todos esses males parecem ser resolvidos por meio de uma economia mais produtiva e mais abundante. Max-Neff (2001) contribui nesse sentido quando esclarece que o crescimento econômico não traz automaticamente o avanço no bem-estar de uma sociedade. O desenvolvimento de fato só ocorre quando há melhoria também em fatores de qualidade de vida, tais como a educação, a saúde a segurança e que estejam aliados na preservação do meio ambiente.

Sachs (1997) ressalta a importância da análise das múltiplas culturalidades e do caminho histórico como uma consequência epistemológica da transformação do conceito de desenvolvimento. Para ele a determinação de trajetórias plurais de desenvolvimento deve ser feita no cruzamento dos ecossistemas e das culturas, através das interações entre a diversidade biológica e a diversidade cultural. Cada geração escreve sua história, e a nossa encontra-se diante do desafio de elaborar uma história dos processos de coevolução da nossa espécie e do nosso planeta.

No que diz respeito ao desenvolvimento sustentável, Oliveira e Souza-Lima (2006, p. 22) explicam que "está focado na necessidade de promover o desenvolvimento econômico satisfazendo os interesses da geração presente, sem, contudo, comprometer a geração futura”.

Para Cavalcanti (2003, p. 33), “o desenvolvimento sustentável é desenvolvimento que satisfaz as necessidades do presente sem comprometer a capacidade de as futuras gerações satisfazerem as suas próprias necessidades".

Pode-se entender por sustentável um modelo econômico, político, social, cultural e ambiental equilibrado, que satisfaça as necessidades das gerações atuais, sem comprometer a capacidade das gerações futuras de satisfazer suas próprias necessidades. Esta concepção começa a se formar e difundir junto com o questionamento do estilo de desenvolvimento adotado, quando se constata que este é ecologicamente predatório na utilização dos recursos naturais, socialmente perverso extremando desigualdade social, politicamente injusto com concentração e abuso de poder, culturalmente alienado em relação aos seus próprios valores e 
eticamente censurável no respeito aos direitos humanos e aos das demais espécies (GRIMM,2010).

Percebe-se que todos os debates levam a preservação do que se tem no presente preocupando-se sempre em manter no futuro, e não é de hoje que essa preocupação tem se tornado motivo de discussão. Para Grimm (2010, p.46), o "conceito de desenvolvimento sustentável é provavelmente o mais amplo, complexo e mais difundido. Sua abrangência é tanto científica quanto política, e diferentes autores e instituições o tem formulado de distintas maneiras".

Há muito tempo já se discute alternativas, teorias e ações que contenham os abusos realizados contra o meio ambiente - teve início ano de 1972, quando o relatório intitulado de The Limits to Growth foi lançado na Conferência das Nações Unidades sobre o Meio Ambiente Humano. Bellen (2002) menciona que na segunda metade do século XX, foi marcada por vários desastres ambientais, como: o da baía de Minamata (no Japão), o acidente de Bhopal (Índia) e o mais conhecido, o acidente na usina nuclear de Chernobyl (União Soviética) que acabaram por favorecer ainda mais as discussões por conta dos impactos causados. Mesmo os desastres ambientais que são danos esporádicos e localizados, proporcionalmente menores que os danos que vêm sendo causados cumulativamente ao meio ambiente (Bellen, 2002, p. 17) e, se pensarmos a médio e longo prazo fica claro que o crescimento populacional, a exaustão dos recursos naturais e a utilização exacerbada de poluentes e componentes químicos tende a cada dia aumentar ainda mais e, não será possível contornar a situação, assim como já está sendo difícil controlar e pensar em alternativas eficazes, conforme apresentado no quadro 1.

Quadro 1: Principais tendências socioeconômicas e suas consequências ambientais

\begin{tabular}{|l|l|}
\hline Principais Tendências Socioeconômicas & \multicolumn{1}{|c|}{ Principais Consequências } \\
\hline Aumento da população & $\begin{array}{l}\text { Pobreza (derivada da má } \\
\text { distribuição da riqueza) }\end{array}$ \\
\hline Urbanização e industrialização & $\begin{array}{l}\text { Escassez de recursos naturais } \\
\text { Contaminação e/ou degradação de } \\
\text { ar, água potável, terras e mares }\end{array}$ \\
\hline $\begin{array}{l}\text { Mudanças no aproveitamento e uso da } \\
\text { terra e dos recursos }\end{array}$ & $\begin{array}{l}\text { Mudanças climáticas globais } \\
\text { Desflorestamento }\end{array}$ \\
\hline $\begin{array}{l}\text { Globalização da economia, tecnologia e } \\
\text { das comunicações }\end{array}$ & Perda de diversidade cultural \\
\hline
\end{tabular}

$$
\text { Fonte: Leis (1999, p. 25). }
$$

O quadro 1 contempla as principais tendências socioeconômicas e principais consequências. É possível mencionar que as necessidades das pessoas, das empresas e das 
políticas para o crescimento e desenvolvimento global, regional ou local geram impactos tidas como irreversíveis.

A expressão do desenvolvimento sustentável tornou-se pública em 1987, quando o relatório "Nosso Futuro Comum", da Comissão Mundial sobre Meio Ambiente e Desenvolvimento, definiu-o como desenvolvimento que satisfaz as necessidades presentes, sem comprometer a capacidade das gerações futuras de suprir suas próprias necessidades (ALMEIDA, 2010, p. 2).

Becker (1997) explica que diante da intensificação do debate sobre a interligação entre questões ambientais e de desenvolvimento (degradação ambiental em curso) problemas publicados pela Comissão Mundial sobre Meio Ambiente e Desenvolvimento, a concepção econômica do desenvolvimento sustentável aponta para novos mecanismos de mercado como solução para condicionar a produção à capacidade de suporte dos recursos naturais, inclusive os de taxação da poluição.

Oliveira e Souza-Lima (2006, p. 22) citam que todas as várias facetas do desenvolvimento sustentável, nos levam às preocupações em cinco temas: i) Preservação da natureza; ii) Desenvolvimento da administração (gerenciamento) e da ciência ecológica nos trópicos; iii) Ambientalismo e crise global; iv) Ecologia global, conservação e meio ambiente e; v) Ambientalismo global.

O peso desta ou daquela causa, pode ser debatido, mas talvez não medido de fato, pois seria imensurável, desde que não tratados como bem econômico, mas como recursos naturais, sabe-se que os indivíduos correm o grande risco da insustentabilidade em geral. Por isso que, atualmente, muito se discute sobre economia verde e PIB verde, pois, em virtude da escassez dos recursos, o mercado acaba inserindo esses bens em sua lógica e, a privatização acaba por precificar os recursos naturais.

Oliveira e Souza-Lima (2006, p. 46) salientam que "enquanto os recursos naturais forem propriedades privadas de uns poucos, as causas profundas da crise ambiental não terão sido enfrentadas de forma crítica [...] a relação da economia ambiental com os recursos naturais está apoiada no princípio da escassez, que classifica como 'bem econômico' o recurso que estiverem em situação de escassez, desconsiderando o que for abundante".

Capra (2006) discorre a respeito:

As últimas duas décadas do século XX vêm registrando um estado de profundo da crise mundial. É uma crise complexa, multidimensional, cujas facetas afetam todos os aspectos de nossa vida - a saúde e o modo de vida, a qualidade do meio ambiente e as relações sociais, da economia, tecnologia e política. É uma crise de dimensões intelectuais, morais e espirituais; uma crise de escala e premência sem precedentes 
em toda a história da humanidade. Pela primeira vez, temos que nos defrontar com a real ameaça de extinção da raça humana e de toda a vida do planeta (p.21).

Percebe-se que o progresso da civilização humana deve transcender diferenças culturais, raciais, religiosas e de gênero, a fim de que o progresso também possibilite melhores condições para a vida humana, já que está relacionado com a noção de evolução social, deixando de lado a ideia calcada nas trevas que o progresso pode gerar à civilização, a partir da ciência, tecnologia e do próprio desenvolvimento.

"É de se estranhar que a natureza seja vista como algo separado de nós" (CURI, 2011, p. 5). Pois o ser humano é fruto da natureza, no entanto, mesmo que as discussões sobre a preservação da espécie e os cuidados com o meio ambiente sejam importantes para a preservação da biodiversidade, o meio ambiente ainda sofre impactos negativas gerado pela ação do homem. Dessa forma, percebe-se que muitas reflexões e discussões ainda precisam ser feitas para que a cultura seja alterada.

\subsection{A Relação Capitalismo, Economia e Meio Ambiente}

"A definição clássica da ação capitalista, que definiu a revolução comercial, foi a acumulação de capital. Com a revolução industrial, a acumulação de capital com incorporação do progresso técnico tornou-se a característica definidora do sistema econômico" (BRESSERPEREIRA, 2005, p. 137).

\footnotetext{
Enquanto ocorriam mudanças nas esferas social e política, as economias experimentaram enorme crescimento e tomaram-se muito mais complexas. Nesse processo, os mercados assumiram um papel importante na coordenação da economia - alocando fatores de produção empregados pelas empresas comerciais —, mas, obviamente, a coordenação de todo o sistema ultrapassou em muito suas possibilidades (BRESSER-PEREIRA, 2005, p. 133).
}

A exposição crescente dos negócios privados a formas variadas de julgamento público, que vão bem além do mercado acabam, por induzir as empresas a agirem em prol do lucro, ou seja, almejam o crescimento, pois, as posturas sustentáveis são caras e implicam muita organização e trabalho. E, se porventura a empresa se desviar disso, consequências serão geradas, assim como os próprios consumidores, quando da decisão, por exemplo, de um consumidor optar pela utilização de sacolas plásticas ou eco bags - são essas decisões que poderão garantir a melhor alocação dos recursos.

No entanto, Perret (2008) chega a citar que a relação entre o capitalismo e o desenvolvimento sustentável seria uma mobilização enganadora. 
Este pensamento nasce das várias mobilizações, encontros, documentos e estratégias que acabam não surtindo efeito algum no que diz respeito à eficácia das ações a seu alcance. Convive-se com um crescimento, que de predatório acaba impossibilitando o desenvolvimento sustentável. De acordo com Perret (2008, p. 14) “o desenvolvimento sustentável não passaria de um brinquedo se não tivesse por vocação tornar-se o novo princípio que dará coerência à ação coletiva. [...] se não houvesse crise ecológica, não se falaria de desenvolvimento sustentável”.

Ao longo do tempo, a emergência para a preservação do meio ambiente foi mostrada ao homem, no entanto, este estava apenas preocupado com as revoluções e descobertas do mundo deixando de lado a importância em se tratar do esgotamento dos recursos; em virtude disso, a crise ambiental aumenta e as classes sociais são alteradas - sendo explicado pela própria autodestruição do homem, quando passa a degradar o meio ambiente. E não é somente isso, as desigualdades entre os países, a pobreza, a política, os aspectos sociais, etc serão afetados pela urgência do socorro ecológico, ou seja, o consumo do bem-estar funciona a curto prazo, assim a lógica do longo prazo da nossa sobrevivência é esquecida. Afinal, a maior preocupação é justificada por um tripé constituído pelos aspectos econômicos, sociais e ambientais. E, se estes não estiverem em perfeita harmonia estaremos fadados a uma grande catástrofe.

\footnotetext{
Por ora, tudo indica que rumamos para uma catástrofe. Ainda é possível limitar seus danos, mas o caminho é estreito. Passar do crescimento atual para um desenvolvimento sustentável a longo prazo não ocorrerá sem mudanças profundas dos modos de produção e de consumo, dificilmente concebíveis sem uma mobilização da sociedade, mobilização da qual o modelo é equivalente a um esforço de guerra [...]. Será preciso demonstrar rigor para pensar, audácia para imaginar e determinação para agir (PERRET, 2008, p. 19-20).
}

O risco de sermos derrotados nessa batalha é grande, pior ainda é pensar que não temos nenhum modelo a ser seguido, tal como discorre Perret (2008) precisamos pensar, imaginar e agir. Nossas vidas são feitas de situações e decisões e, nossas decisões não deveriam pensar apenas no progresso, mas nos sinais de exaustão que este também tem nos mostrado.

Neste sentido, muitos estudos defendem que o capitalismo é um conceito contraditório, pois, se na maioria das vezes é conceituado pela perspectiva do crescimento, o quê, não estaria visando a sustentabilidade, já que estaríamos promovendo inovação tecnológica e novas formas de aperfeiçoamento daquilo que já temos, contrariando muitas 
vezes os conceitos de qualidade de vida, bem-estar, etc. - em resumo um mundo bom de se viver.

Mas, falando em Bem Viver, talvez até mesmo este conceito esteja sendo distorcido, pois o que pode ser considerado um mundo bom para se viver para uns, é tratado de forma diferente para outros. Bem viver, ou "Bien Vivir" ou "Vivir Bien” em termos ideológicos, o conceito implica a reconstituição da identidade cultural de herança milenária, a recuperação de conhecimentos e saberes antigos; uma política de soberania e dignidade nacional; a abertura de novas formas de relação de vida (não individualista senão comunitária), a recuperação do direito de relação com a Mãe Terra e a substituição da acumulação ilimitada individual de capital pela recuperação integral do equilíbrio e a harmonia com a natureza (MAMANI, 2010, p. 13).

Abramovay (2012) traz a ideia de que uma nova economia serviria para traçar uma relação de limites entre a sociedade e a natureza, com isso, o desenvolvimento seria possibilidade se, fossem reconhecidos os limites dos ecossistemas, assim, os homens seriam capazes de substituir os recursos exauridos e reparar os danos causados em tempo hábil.

Mas é sabido que isso seria uma utopia, e com o tempo a noção de limite se tornaria supérflua, já que as depredações do meio ambiente vão além do controle do homem, tal como as mudanças climáticas.

O outro importante ponto seria a inovação. Abramovay (2012) aponta que o limite e a inovação devem caminhar juntos, mas que não se deve olhar a inovação com os olhos no aumento de produtividade, mas sim, o de melhorias de como se obter e transformar a energia, os materiais e a própria biodiversidade em produtos e serviços úteis para a sociedade. Seria um sistema orientado para a inovação, com vistas a favorecer a sustentabilidade.

Logo, a necessidade de se criar uma nova economia, deveria ser em favor do meio ambiente, para que pudéssemos devolver a ele o que ele nos gera. É por esse motivo, que retomamos o conceito de escassez, afinal a economia é considerada a ciência da escassez.

\subsection{Bem Viver e a Mudança de Paradigma}

O sistema de valores e a base da nossa cultura devem ser reestruturados, pois "a economia do bem-estar persistiu até os dias atuais, embora tenha sido mostrado de forma concludente que a soma das preferências pessoais não equivale à escolha social. Muitos críticos contemporâneos veem nisso uma desculpa mal disfarçada para o comportamento egoísta que abala qualquer conjunto coeso de metas sociais, tornando a política ambiental caótica" (CAPRA, 2006, p. 197). 
Por isso que, em meio a mudança de paradigma é necessário que repensemos nosso modo de viver, ou seja, agora não é somente o homem o centro das atenções, mas sim as relações traçadas entre o homem e a natureza. Que nos faz refletir sobre as condições necessárias para garantir nossa sobrevivência e a qualidade da mesma, revelando assim, uma ideia de coletividade e solidariedade.

Em virtude disso, desde a década de 1960 estudiosos vem buscando discutir novas soluções, a fim de diminuir a degradação do meio ambiente, favorecendo "outros mundos possíveis" - ou seja, a ideia de Bem Viver vai contra os preceitos do capitalismo, quando Acosta (2009) diz que se busca uma economia distinta, uma economia social e solidária, diferente daquela caracterizada por uma suposta livre concorrência, que favorece o canibalismo econômico entre seres humanos e é ela quem tem alimentado a especulação financeira, por isso busca-se construir relações de produção, de troca e cooperação que propiciem a eficiência e qualidade.

Percebe-se então, que há a necessidade de promover uma boa relação entre Estado, Mercado e Sociedade para fortalecer o desenvolvimento sustentável.

\begin{abstract}
Nos encontramos diante de uma nova condição planetária histórica a qual podemos reconhecer claramente, que se trata de nada menos que uma crise civilizatória, da impossível continuidade do modelo industrialista e depredador, baseado na luta dos direitos humanos contra a natureza, e na identificação do bem estar e da riqueza como acumulação de bens materiais, com as consequentes expectativas de crescimento e consumo ilimitados, de mais a mais, isto, sinceramente, não é possível (ACOSTA et al., 2009, p. 31).
\end{abstract}

Enquanto isso a capacidade produtiva da vida e a subsistência ficam relegados, pois nos tornamos reféns em boa parte de um sistema egoísta/capitalista, precisamos de uma nova economia, de um novo modo de ver e fazer o desenvolvimento acontecer. "Hoje o uso de recursos dos quais depende a reprodução social não atende ao propósito de favorecer a ampliação permanente das liberdades substantivas dos seres humanos, apesar da imensa crescente prosperidade material" (ABRAMOVAY, 2012, p. 15).

Assim, uma das alternativas encontradas para que a economia trabalhe em prol do meio ambiente é a agricultura sustentável, que apesar de ter surgido recentemente, em virtude do declínio da agricultura moderna, é uma técnica que vem melhorando as condições dos recursos naturais buscando entender o funcionamento dos agroecossistemas - protegendo assim a produtividade e o tempo de conservação dos recursos naturais, ou seja, vai além do uso de práticas alternativas e do desenvolvimento de agroecossistemas, pois trabalha com 
interações ecológicas e sinergismos entre os componentes biológicos, ocasionando a própria recuperação e fertilidade do solo.

\begin{abstract}
A agroecologia, segundo Altieri (2012, p. 105) "emerge como uma disciplina que disponibiliza os princípios ecológicos básicos sobre como estudar, projetar e manejar agroecossistemas que sejam produtivos e ao mesmo tempo conservem os recursos naturais, assim como sejam culturalmente adaptados e social e economicamente viáveis. A agroecologia extrapola a visão unidimensional dos agroecossistemas (genética, edafologia, entre outros) para abarcar um entendimento dos níveis ecológicos e sociais da coevolução, estrutura e funcionamento".
\end{abstract}

Não é tão fácil assim, para que haja o efetivo funcionamento da agroecologia há alguns princípios ecológicos a serem seguidos (REINJNTJES et al., 1992):

$\checkmark$ Aumentar a ciclagem de biomassa e otimizar a disponibilidade e fluxo equilibrado de nutrientes;

$\checkmark$ Assegurar solo com condições favoráveis para o crescimento das plantas, particularmente por meio do manejo de matéria orgânica e do incremento de sua atividade biológica;

$\checkmark$ Minimizar as perdas decorrentes dos fluxos de radiação solar, ar e água por meio do manejo do microclima, da captação de água e da cobertura do solo;

$\checkmark$ Promover a diversificação inter e intraespécies no agroecossistema, no tempo e no espaço;

$\checkmark$ Aumentar as interações biológicas e os sinergismos entre os componentes da biodiversidade promovendo processos e serviços ecológicos.

As técnicas citadas buscam aumentar a eficiência biológica geral, a capacidade produtiva e a autossuficiência, isso sob uma perspectiva de manejo provocaria uma retroalimentação, onde o agroecossistemas aproveitariam essa imitação da natureza utilizando a radiação solar, os nutrientes do solo e a chuva para se autorregular. De acordo com Altieri (2012, p. 107) alguns processos devem ser otimizados para que isso possa acontecer: i) fortalecer a imunidade do sistema (funcionamento apropriado do sistema natural de controle de pragas); ii) diminuir a toxicidade por meio da eliminação de agroquímicos; iii) otimizar a função metabólica (decomposição da matéria orgânica e ciclagem de nutrientes); iv) equilibrar os sistemas regulatórios (ciclos de nutrientes, equilíbrio de água, fluxo de energia, regulação de populações, etc); v) aumentar a conservação e a regeneração do solo, da água e da biodiversidade e; vi) aumentar e manter a produtividade no longo prazo

Todos estes processos ecológicos funcionariam de modo a reproduzir a função e estrutura dos ecossistemas naturais. Com isso seriam melhoradas a sustentabilidade econômica e ecológica dos agroecossistemas. Diferente das técnicas tradicionais que são 
intensivas em conhecimento não em insumos, tal como a agroecologia, no entanto, ambas necessitam de adaptações e alterações e o mais importante, talvez a tarefa mais difícil da agroecologia é traduzir os princípios e técnicas para aumentar a produção, estabilidade e resiliência dos sistemas produtivos. No quadro 2 apresenta-se as diferenças estruturais e funcionais entre os agroecossistemas e os ecossistemas naturais.

Quadro 2: diferenças estruturais e funcionais entre os agroecossistemas e os ecossistemas naturais

\begin{tabular}{|c|c|c|}
\hline CARACTERÍSTICAS & AGROECOSSISTEMAS & ECOSSISTEMA NATURAL \\
\hline Produtividade líquida & Alta & Média \\
\hline Cadeias tróficas & Simples, lineares & Complexas \\
\hline Diversidade de espécies & Baixa & Alta \\
\hline Diversidade genética & Baixa & Alta \\
\hline Ciclos minerais & Abertos & Fechados \\
\hline Estabilidade (resistência) & Baixa & Alta \\
\hline Entropia & Alta & Baixa \\
\hline Controle humano & Definido & Desnecessário \\
\hline Permanência temporal & Curta & Longa \\
\hline $\begin{array}{l}\text { Heterogeneidade do } \\
\text { habitat }\end{array}$ & Simples & Complexa \\
\hline Fenologia & Sincronizadas & Estacional \\
\hline Maturidade & Imatura, sucessão inicial & Madura, clímax \\
\hline
\end{tabular}

Fonte: Gliesmann (1998), adaptado por Altieri (2012, p. 108).

O quadro 2 mostra que ambos os processos ainda necessitam de várias adaptações e alterações, mas só de pensar que a agroecologia preza por uma produção além de lucrativa, que possui uma intenção maior de preservar o meio ambiente e ainda ocasionar de maneira natural sua recomposição, isso por si só já poderia encorajar os indivíduos. No entanto, não se pode iludir que esta consciência aconteça de imediato, pois é necessário aparato governamental (políticas públicas), da participação dos produtores do ecossistema natural, da conscientização da sociedade em geral - por conta de discursos que promovam o pensamento efetivamente sustentável, entre outros. Até porque os estudos sobre o meio ambiente limitamse na maioria das vezes às ciências sociais e políticas.

\subsection{A agroecologia no município de Maracás}

O Município de Maracás, localizado do Território Vale do Jiquiriçá, abriga três comunidades rurais que foram contempladas com o Programa Sementes Crioulas, realizado pela Articulação Semiárido - ASA e o Centro de Convivência e Desenvolvimento 
Agroecológico do Sudoeste da Bahia - CEDASB. As comunidades são: Candial, Quatro Lagoas e Agreste, Gavião e Cachoeirinha - todas inseridas no bioma caatinga.

O projeto se desenvolveu a partir da parceria com o Sindicato dos Trabalhadores Rurais, onde contemplava a incorporação de tecnologias sociais como cisternas calçadão, formações na área de agroecologia, hortas comunitárias e um banco de sementes crioulas em cada comunidade contemplada. A escolha do local para a realização dos estudos se deve as essas experiências de transição agroecológicas com o apoio dessas organizações que promovem a Agroecologia.

Em especial, os bancos de sementes, nestas localidades teve como objetivo resgatar os saberes tradicionais, preservar as espécies cultivadas nas comunidades por gerações, bem como promover a autossuficiência dos associados e associadas no abastecimento de sementes de determinadas espécies vegetais importantes para a agricultura local, por meio das trocas de sementes crioulas. Nesse sentido, pode-se observar que a relação com o processo de transição agroecológica e o bem viver se configura no momento em que as comunidades (Figura 1) despertaram e resgataram memórias de como viviam seus antepassados e de como é possível viver numa região do semiárido baiano, desprovido de chuvas abundantes para o consumo d'água e as lavouras e todas as dificuldades impostas pela "indústria da seca".

Figura 1 - Comunidade do Candial e Quatro Lagoas que integram o Banco de Sementes Crioulas

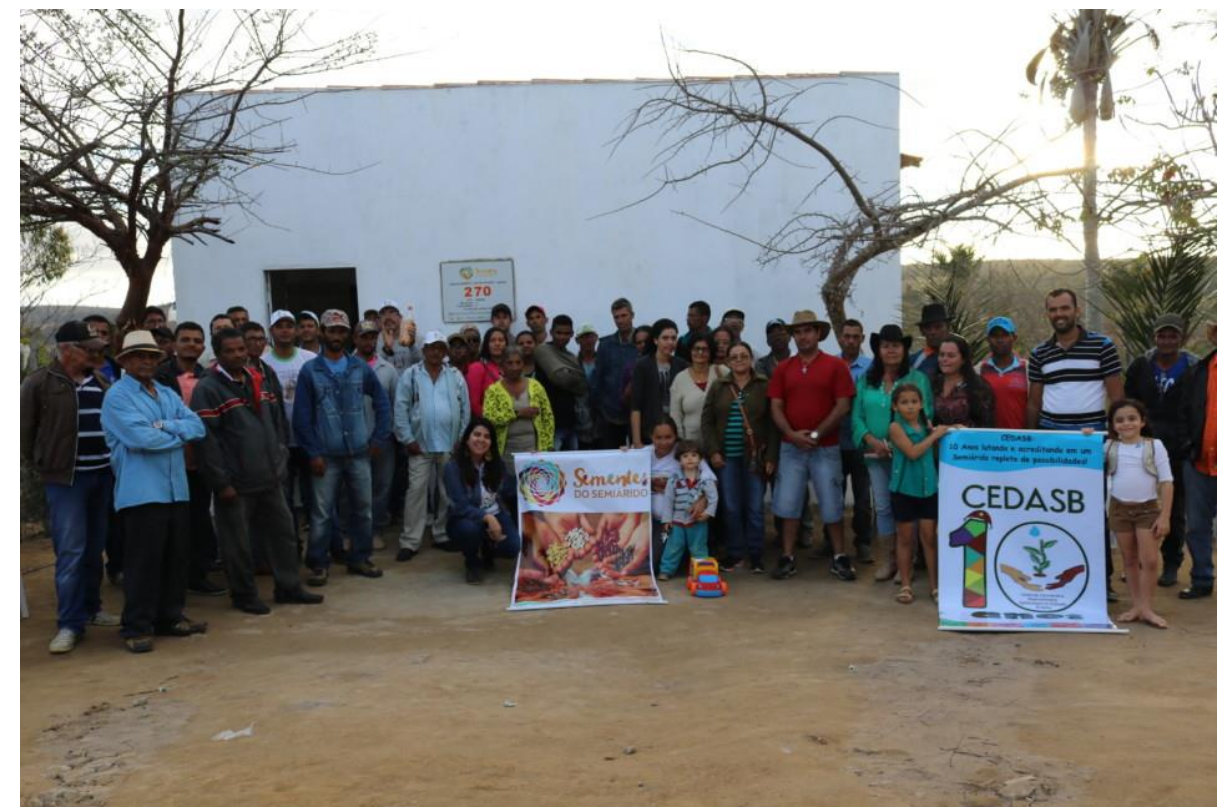

Fonte: CEDASB, 2016. 
Após a implantação deste projeto, as comunidades criaram um grupo conhecido como Grupo de Mulheres Produtivas, onde a cada tarde de domingo elas se reúnem para um encontro de costuras, bordados, produção de biscoitos, óleos de coco licuri, prosas, risadas e cantigas. As produções são vendidas na feira livre que acontecem aos sábados no município de Maracás e na Feira da Diversidade Cultural e Agroecológica, realizada na praça principal da cidade toda primeira quarta do mês. O projeto trouxe o fortalecimento da capacidade organizativa dos agricultores, exercendo papel de liderança, participante de espaços públicos de participação como o Conselho Municipal de Meio Ambiente - CMMA, o Conselho Municipal de Desenvolvimento Rural Sustentável - CMDRS, bem como o Colegiado Territorial do Vale do Jiquiriçá.

Em 2016, foi realizado o Encontro dos Bancos de Sementes, onde se reuniram representantes das comunidades rurais de Cachoeirinha, Gavião e Candial (Figura 2), com o objetivo de avaliar o projeto e apontar novas perspectivas.

Figura 2 - Encontro dos Bancos de Sementes Crioulas, setembro de 2016

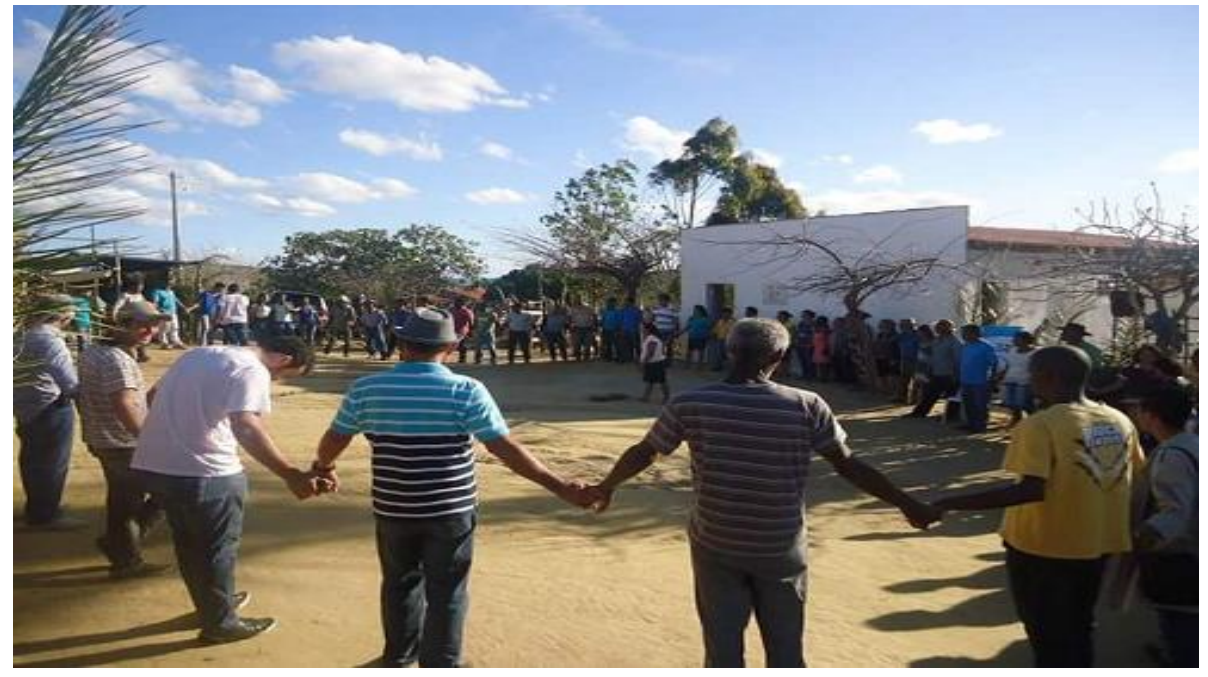

Fonte: Queiroz, 2016.

O encontro, fez compreender que os processos agroecológicos, é muito mais do que plantar e colher, é um modo de vida, a forma como estabelecemos relações sociais e familiares. É o preocupar-se com o outro respeitando seus anseios e limites, é romper com a hegemonia do agronegócio e construir alternativas de autogestão, produção justa, que possam libertar os trabalhadores rurais, camponeses, povos das florestas para que tenha autonomia para empreender e decidir, sem precisar ficar preso na rede de atravessadores e do comércio de sementes convencionais e transgênicas.

\section{Considerações finais}


A partir dos dados observados e da literatura disponível considera-se que os preceitos do Bem Viver podem favorecer mundos possíveis (contra os preceitos egoístas do capitalismo), repensar nosso modo de viver e, traçar uma relação entre estado, mercado e sociedade, favorecendo o desenvolvimento sustentável. Os postulados do desenvolvimento sustentável levam em conta: deixar de considerar o desenvolvimento apenas como crescimento, analisando também questões que transcendem diferenças culturais, raciais, religiosas e de gênero, proporcionando qualidade de vida.

Contudo, foi possível compreender que o capitalismo, possuindo um conceito contraditório, leva à necessidade de se conceber novas formas de produção e de economia, estabelecendo limites entre a sociedade e a natureza. Tal relação deve possibilitar a substituição dos recursos exauridos e reparar os danos causados em tempo hábil, mesmo que isso fosse utópico - já que as depredações do meio ambiente vão além do controle do homem, tal como as mudanças climáticas.

Logo, a necessidade de se criar uma nova economia, deveria ser em favor do meio ambiente, para que se possa devolver a ele o que ele nos gera. Diante disso o estudo de caso permitiu identificar e analisar os territórios, do Vale do Jiquiriçá e do Médio Rio de Contas, região que possui uma rica diversidade ambiental de Caatinga e Mata de Cipó.

Como resultado, foi possível identificar que nas comunidades estudadas existe uma riqueza de saberes e os principais benefícios observados foram a capacidade organizativa, a melhoria dos sistemas produtivos, a conservação ambiental dos recursos naturais e a valorização da sociobiodiversidade a partir do resgate e do uso de sementes crioulas, a segurança alimentar e nutricional com a diversificação dos plantios, como milho, feijão, ervilha, mandioca, andu, palma, frutas, hortaliças, além disso observou a geração de renda a partir da Feira da Diversidade Cultura e Agroecológica e dos mercados locais, e das feiras promovidas em determinado período do ano pelo Colegiado Territorial com o apoio do Governo do Estado da Bahia. De modo geral, podemos compreender que esses benefícios podem ser entendidos como um processo de Bem Viver agroecológico. Por outro lado, a preocupação refere-se ao Bem Viver dos nativos da região, que são prejudicados com a falta de pastos para alimentar os animais e a falta de água para irrigação das lavouras, isso devido a degradação ambiental e as mudanças climáticas na região.

Neste contexto, foi possível concluir que a mudança de paradigmas vem mostrando que algumas decisões, relacionadas com a recomposição dos recursos escassos do meio ambiente, se tornarão obrigatórias e, até mesmo o egoísmo imposto pelo capitalismo terá que 
sofrer adaptações, se as instituições quiserem sobreviver. Portanto, processos produtivos entendidos como mais sustentáveis, visam garantir processos mais limpos, duradouros e que podem tentar garantir a permanência da competitividade com uso de recursos produtivos, mesmo as inovações tecnológicas, para que as organizações sobrevivam dos meios.

Por outro lado, o ser humano, mesmo que venha prorrogando as decisões no que diz respeito a natureza, com o pensamento que esta será infinita, percebe-se que, mesmo que a passos lento, há certa mudança e quebra de paradigmas.

Ou seja, o capitalismo preocupado apenas com o lucro, consumo e acumulação, passa a cumprir com as obrigatoriedades que a Lei impõem, percebendo-se desse modo, avanços na preocupação com o meio ambiente e por si só com a sustentabilidade. Entre os avanços, podem ser citados as inovações tecnológicas com vistas a favorecer a sustentabilidade, a exemplo das melhorias para se obter e transformar a energia, os materiais e a própria biodiversidade em produtos e serviços úteis para a sociedade.

\section{Referências}

ABRAMOVAY, R. Muito além da economia verde. São Paulo: Editora Abril, 2012.

ACOSTA, Alberto et al. El buen vivir: Una vía para el desarrollo. Quito, Equador, 2009. ALCANTARA, L.C.; SAMPAIO, C.A.C. Bem Viver como paradigma de desenvolvimento: utopia ou alternativa possível? Revista Desenvolvimento e Meio Ambiente, v. 40, p. 231-251, abril 2017.

ALCANTARA, L.C.; GRIMM, I, J. Desenvolvimento e relações de gênero: bem viver na construção de projetos de ação territorial, 2017. No prelo.

ALMEIDA, L. N. Sustentabilidade ambiental como estratégia empresarial na rede walmart. Disponível em: < http://www.aedb.br/seget/artigos10/235_Sustentabilidade\%20Ambiental\%20e\%20Estrategia \%2 0Empresarial\%20na\%20Rede\%20Walmart.pdf>. Acesso em: 23 abr. 2017.

ALTIERI, M. Agroecologia: bases científicas para uma agricultura sustentável. $3^{\text {a }}$ ed., rev. ampl., São Paulo, Rio de Janeiro: Expressão Popular, 2012.

I. ASSIS, Renato Linhares de. Desenvolvimento rural sustentável no Brasil: perspectivas a partir da integração de ações públicas e privadas com base na agroecologia. vol.10, nº.1, Ribeirão Preto, Jan./Mar. 2006.

BECKER, D. F. Desenvolvimento sustentável: Necessidade e/ou Possibilidade? Rio Grande do Sul: Edunisc, 1997.

BELLEN, H. M. V. Indicadores de sustentabilidade: uma análise comparativa. Santa Catarina, nov. 2002. Tese (Doutorado em Engenharia de Produção), Universidade Federal de Santa Catarina - UFSC. 
BRESSER-PEREIRA, L. C. Capitalismo dos técnicos e democracia. Revista Brasileira de Ciências Sociais, 20 (59), outubro 2005: 133-148. Disponível em: http://www.bresserpereira.org.br/papers/2005/05.capitalismotecnicos_democracia.web.pdf.

Acessado em: 23 abr. 2017.

CAPRA, FRITJOF. O ponto de mutação. Tradução Álvaro Cabral, São Paulo: Cultrix, 2006.

CAVALCANTI, C. Desenvolvimento e natureza: estudos para uma sociedade sustentável. $4^{\text {a }}$ ed., São Paulo: Cortez: Recife: PE: Fundação Joaquim Nabuco, 2003.

CEDASB, 2016. Centro de Convivência e Desenvolvimento Agroecológico do Sudoeste da Bahia. 2016. Disponível em:<http://cedasb.org.br/category/galeria/fotos/page/2/> Acessado em: 01 Ago. 2017.

QUEIROZ, Iala Serra. Visita a campo nas comunidades rurais do Município de Maracás. 19 de setembro de 2016.

GIL, A. C. Métodos e técnicas de pesquisa social. São Paulo: Atlas, 1994.

GRIMM, I.J. Planejamento territorial: uma metodologia de monitoramento de indicadores socioambientais na microbacia hidrográfica do Rio Sagrado, Morretes (PR). Dissertação de Mestrado. Programa de Pós-Graduação em Desenvolvimento Regional da Universidade Regional de Blumenau, Santa Catarina, 2010. 250p.

IBGE - Instituto Brasileiro de Geografia e Estatística. Censo Populacional 2010. Disponível em: <http://biblioteca.ibge.gov.br/visualizacao/dtbs/bahia/maracas.pdf. $>$. Acesso em: $27 \mathrm{de}$ jul. 2017.

LEIS, H. R. A modernidade insustentável: as críticas do ambientalismo à sociedade contemporânea. Rio de Janeiro: Petrópolis: Vozes: Santa Catarina: UFSC, 1999.

MAMANI, F. H. Buen Vivir/Vivir Bien. Filosofia, políticas, estratégias y experiências regionales andinas. Coordinadora Andina de Organizaciones Indígenas - CAOI. Lima, Peru: 2010.

MAX-NEEF. M. Desarrollo a Escala Humana. Montevideo: Nordam comunidad, 2001.

PERRET, Bernard. O capitalismo é sustentável? Traduzido por Editions Carnets Nord, 2008.

REIJNTJES, C. HAVERKORT, B. WATERS-BAYER, A. Farming for the future. Londres: MacMillan Press Ltd., 1992.

SACHS, Ignacy. Estratégias de transição para o século XXI: Desenvolvimento e meio ambiente. São Paulo: Nobel; 1997, p. 25 - 35.

SALVADOR, A. D. Métodos e técnicas de pesquisa bibliográfica. Porto Alegre: Sulina, 1986.

THEODORSON, G. A. THEODORSON, A. G. A modern dictionary of sociology. London, Methuen, 1970. 
RELACult - Revista Latino-Americana de Estudos em Cultura e Sociedade

Revista Latinoamericana de Estudios en Cultura y Sociedad | Latin American Journal of Studies in Culture and Society V. 03, ed. especial, dez., 2017, artigo $\mathrm{n}^{\circ}$ 578 | relacult.claec.org |e-ISSN: 2525-7870

VASCONCELlOS, M.A. GARCIA, M.E. Fundamentos de economia. São Paulo: Saraiva, 1998. 